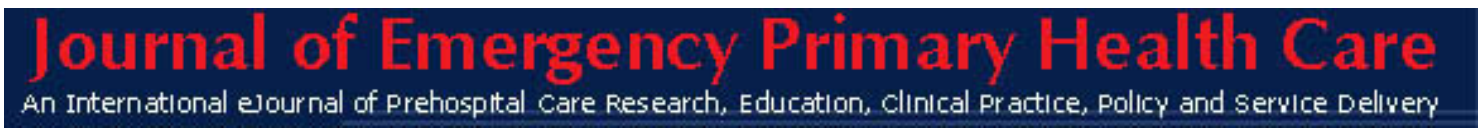

ISSN 1447-4999

\title{
CLINICAL PRACTICE
}

Article 990190

\author{
Brief Review of Procedural Sedation \& Analgesia \\ Dr. Gregory P. Neyman M.D. \\ Emergency Department Medical Director \\ Henry County Health Center \\ Mt. Pleasant, Iowa 52641, USA
}

\section{Introduction}

Procedural sedation and analgesia (formerly referred to as Conscious Sedation) can be a very valuable tool in the armamentarium of the physician practicing in the emergency setting. Several studies have shown it is (probably) underutilized. When asked why, the most common response was "lack of training (for both the physician and other personnel).",1,4 This article will review some of the clinical issues regarding procedural sedation and analgesia.

\section{Definition}

Procedural sedation and analgesia (PS\&A) is a minimally depressed level of consciousness that retains the patient's ability to maintain a patent airway independently, continuously and respond appropriately to physical stimulation and verbal commands. PS\&A may be administered during therapeutic, diagnostic or surgical procedures. The drugs, dosages and techniques utilized for PS\&A are not intended to produce loss of consciousness. The level of consciousness encountered during PS\&A should be distinguished from two other levels of consciousness: deep sedation and general anesthesia. Deep sedation is a controlled state of depressed consciousness or unconsciousness from which the patient is not easily aroused, accompanied by a partial or complete loss of protective reflexes, including the ability to maintain a patent airway independently and respond purposefully to physical stimulation or verbal command. General anesthesia is a controlled state of unconsciousness accompanied by a loss of protective reflexes, including loss of the ability to maintain a patent airway or to respond purposefully to physical stimulation or verbal command. ${ }^{2,3,4,7}$

In actuality, a continuum exists among conscious sedation, deep sedation and general anesthesia. The patient's age and preexisting medical conditions may significantly alter the dosing requirements needed for PS\&A. If either deep sedation or general anesthesia is required for the procedure, skilled anesthesia personnel should be available to assist in the management of the patient. ${ }^{1,4}$

\section{Personnel and Preparation}

The recommended minimum number of personnel involved in the care of patients undergoing PS\&A during the entire procedure should be two: (1) the physician who performs the diagnostic, therapeutic or surgical procedure; and (2) the individual (M.D., D.O., R.N., P.A. or R.T.) who monitors the patient and his/her response to both the sedation and the procedure and who is capable of assisting with any supportive or resuscitative measures. One of these 
two personnel must be available to the patient from the time the procedure has been completed until the time the patient has adequately recovered or has been turned over to personnel performing recovery care. The individual who monitors the patient should have no other significant responsibilities, i.e., no tasks or duties which would compromise his/her ability to monitor the patient. In certain circumstances, e.g., when the patient has been identified as "high risk" or when the procedure to be carried out is particularly complex, a third individual or member of the anesthesia care team should be present to assist with the procedure. $2,4,6,9,10$

Clinicians who perform PS\&A should be competent in airway management and resuscitation measures (i.e., BLS, ACLS) and should be educated regarding and demonstrate knowledge in the use, side effects and complications of the medication to be given. The individual responsible for monitoring the patient should have the aforementioned skills and should also have knowledge and experience in the use of oximetry and, when applicable, cardiac monitoring equipment and in the recognition of cardiac arrhythmias. ${ }^{1,3,5,6}$

\section{Location/Equipment/Monitoring}

The room where the procedure utilizing PS\&A is scheduled to take place should have adequate, uncluttered floor space (to accommodate emergencies) and be equipped with:

- a source and means for providing supplemental oxygen;

- Various sized airways and a self inflating positive-pressure oxygen delivery system capable of delivering $100 \%$ oxygen at a 15 liter/minute flow rate for at least 60 minutes.

- a source of suction;

- the pharmaceutical agent to be used and its reversal agent;

- a pulse oximeter with alarm;

- a device for taking blood pressure;

- a cardiac monitor with alarm: recommended for patients with an ASA classification of III or greater or with a history of cardio-pulmonary disease; and

An emergency cart should be immediately accessible to the room where the procedure is to take place. Means for notifying emergency support services such as respiratory therapy and code pages should be clearly identified and posted in the PS\&A location. $2,3,7,9,10$

\section{Prior to Procedure}

It should be ascertained:

- the patient's state of consciousness and medical condition are appropriate for the use of conscious sedation;

- the patient's American Society of Anesthesiologist's Physical Status Classification (ASA) is determined (seeTable 1);

- $\quad$ preparatory studies appropriate to the procedure and patient have been done;

- the patient has no allergy or sensitivity to the prescribed medication (see Table 2 for medication examples); 
- the patient's pertinent medical history, including current drug regimen, has been obtained/reviewed;

- the patient has been NPO for at least six hours prior to the planned procedure, except for clear liquids which may be given up to two hours before the procedure.

- informed consent has been obtained. The patient/guardian must be informed of the risks and alternatives to PS\&A; documentation must be in the medical record prior to procedure;

- a physical exam has been conducted which includes assessing/measuring the patient's:

o estimated weight,

o vital signs (baseline blood pressure; heart rate; respiratory rate, pattern and quality),

o baseline oxygen saturation,

o airway (i.e., an evaluation performed in anticipation of possible intubation, e.g., checking condition of teeth; range of neck motion; ability to open mouth),

o chest and cardiac status,

o general neurologic status (e.g., assessing mental status; presence or absence of stroke deficits), and

o physical status (e.g., ASA physical status category);

- the patient has a functioning IV line;

- the patient's oxygen requirements are evaluated.;

- the patient has been instructed to report any problems associated with the procedure or the PS\&A (e.g., pain, difficulty in breathing) to the individual responsible for monitoring the patient.

If any difficulty with the patient or procedure is anticipated, appropriate medical consultation should be obtained or another type of procedure considered., $3,4,6$,

\section{During the Procedure}

The individual responsible for monitoring the patient should ascertain and record:

- $\quad$ all medication administered (route, site, time, drug, dose);

- the amount and means of oxygen administered;

- the patient's vital signs every 5-10 minutes. If the patient has been classified ASA III or greater or has a history of cardio-pulmonary disease, the heart rate and rhythm should be displayed continuously by cardiac monitor; and

- the patient's oxygen saturation every 5-10 minutes.

The patient's head position should be checked frequently to ensure a patent airway. If the patient becomes unstable during the procedure, appropriate medical consultation should be sought immediately. ${ }^{5,7,9}$ 


\section{Following the Procedure}

The individual whose responsibility it is to monitor the patient should ascertain and record the patient's vital signs (as defined directly above) every 5 - 10 minutes for a minimum of 30 minutes following the last administered dose of IV sedation. Beyond this 30 minute period and, if stable, vital signs should be recorded every 15 minutes until the patient returns to his/her pre-procedure state. Oxygen saturation levels should be obtained if indicated. The patient must be observed for a minimum of 30 minutes following the procedure.

Discharge criteria should include:

- patient has stable vital signs and oxygen saturation level;

- $\quad$ patient's swallow, cough and gag reflexes are present, or appropriate to baseline;

- patient is alert or appropriate to baseline;

- patient can sit unaided if appropriate to baseline and procedure;

- $\quad$ patient can walk with assistance if appropriate to baseline and procedure;

- $\quad$ nausea and dizziness are minimal;

- $\quad$ hydration is adequate;

- dressing/procedure site have been checked if applicable; and

- discharge order has been written by physician. An R.N. may discharge the patient utilizing appropriate criteria based upon a prior discharge order.

If the procedure was done on an outpatient or ambulatory care basis, the patient should be given: (1) written instructions that include an explanation of potential or anticipated limitations on activities, behavior and diet; and (2) a 24-hour emergency contact prior to discharge. Ambulatory care patients should not leave the premises unless they are under the care of a competent adult; they should be advised to refrain from operating heavy machinery, driving a care, consuming alcohol and making important decisions for 12 to 24 hours. ${ }^{1,3,4,5,7,9}$

\section{Conclusion}

Procedural sedation and analgesia is an excellent way to perform diagnostic, therapeutic and/or surgical procedures with comfort to the patient. Adequate training, preparation and ultimately experience will allow the physician working in the emergency setting to utilize the valuable tool. 


\section{References}

1. Cammarano WB, Drasner K, Katz JA. Pain control, sedation, and use of muscle relaxants. In: Hall J, Schmidt GA, Wood LH, eds. Principles of Critical Care. 2nd ed. McGraw-Hill; 1998.

2. Chernow B, ed. Essentials of Critical Care Pharmacology. Baltimore, Md: Lippincott Williams \& Wilkins; 1989.

3. Kim MK, Strait RT, Sato TT. A randomized clinical trial of analgesia in children with acute abdominal pain. Acad Emerg Med 2002 Apr; 9(4): 281-7[Medline].

4. Freeman ML. Sedation and monitoring for gastrointestinal endoscopy. In: Yamada T, ed. Textbook of Gastroenterology. Philadelphia, Pa: Lippincott, Williams \& Wilkins; 1999 2660-

5. Walls RM. Airway Management. In: Emergency Medicine Concepts and Clinical Practice. 4th ed. St. Louis, Mo: Mosby-Yearbook; 1998: 2-24.

6. Aranda M, Hanson CW. Anesthetics, sedatives, and paralytics. Understanding their use in the intensive care unit. Surg Clin North Am 2000 Jun; 80(3): 933-47, x-xi[Medline].

7. Blanda M, Gallo UE. Emergency airway management. Emerg Med Clin North Am 2003 Feb; 21(1): 1-26[Medline].

8. The pediatric patient. Pediatric Emergency Medicine Committee of the American College of Emergency Physicians. Ann Emerg Med 1996 Jul; 28(1): 55-74[Medline].

9. Roberts JR, Hedges JR, Dronen SC. Pharmacologic Adjuncts to Intubation. In: Clinical Procedures in Emergency Medicine. 3rd ed. Philadelphia, Pa: WB Saunders Co; 1998: 45-57.

10. Vinson DR, Bradbury DR. Etomidate for procedural sedation in emergency medicine. Ann Emerg Med 2002 Jun; 39(6): 592-8[Medline].

Author Disclosure

The author has no financial, personal or honorary affiliations with any commercial organization directly involved or discussed in this study.

This Article was peer reviewed for the Journal of Emergency Primary Health Care Vol.4, Issue 1, 2006 


\section{TABLE 1}

\section{American Society of Anesthesiologists Physical Status Classification}

\section{Class I}

There is no organic, physiological, biochemical or psychiatric disturbance. The pathologic process for which operation is to be performed is localized and is not a systemic disturbance.

\section{Class II}

Mild to moderate systemic disturbance caused either by the condition to be treated surgically or by other pathophysiological processes.

\section{Class III}

Severe systemic disturbance or disease from whatever cause, even though it may not be possible to define the degree of disability with finality.

\section{Class IV}

Indicative of the patient with severe systemic disorder already life-threatening, not always correctable by the operative procedure.

\section{Class V}

The moribund patient who has little chance of survival but is submitted to operation in desperation.

\section{TABLE 2}

\section{Drugs and Dosages for Sedation}

This is not intended to be all-inclusive, but should serve as a guide to an upper safe limit for those individuals not having extensive experience with the use of these medications. Some physicians use etomidate which generally causes "deep sedation" and is beyond the scope of this article.

Certain patients may not tolerate even these recommended doses. Furthermore, many of these medications have synergistic respiratory depressant effects; when administered in combination these drugs should be used at lower than those stated below.

*Source: "Model Guideline for Sedation by Non-Anesthetists During Diagnostic and Therapeutic Procedures," Risk Management Committee, Departments of Anesthesia, Harvard Medical School.” 


\begin{tabular}{|c|c|c|}
\hline Medication & Dose & Comments \\
\hline \multicolumn{3}{|l|}{ Sedatives } \\
\hline Lorazepam & $\begin{array}{l}.044-.050 \mathrm{mg} / \mathrm{kg} \text { IV } \\
.050 \mathrm{mg} / \mathrm{kg} \mathrm{IM}\end{array}$ & $\begin{array}{l}\text { Onset: } 2-6 \mathrm{~min} \text {. (IV// } 15-30 \mathrm{~min} \text { ( IM) } \\
\text { Peak: } 15-20 \mathrm{~min} \text {. (IV)/ 1-2 hr. (IM) } \\
\text { Duration: variable (up to } 48 \mathrm{hrs} \text { ) }\end{array}$ \\
\hline Diazepam & $\begin{array}{l}0.1 \mathrm{mg} / \mathrm{kg} \text { IV slowly } \\
\text { (over } 3 \mathrm{~min} \text {.) } \\
5-10 \mathrm{mg} \mathrm{IM}\end{array}$ & $\begin{array}{l}\text { Onset: } 1-5 \mathrm{~min} \text { ( (IV)/ } 10-20 \mathrm{~min} \text { ( IM) } \\
\text { Peak: } 15-30 \mathrm{~min} \text {. (IV)/30-90 min. (IM) } \\
\text { Duration: variable }\end{array}$ \\
\hline Droperidol & $\begin{array}{l}0.02-0.05 \mathrm{mg} / \mathrm{kg} \mathrm{IV} \\
\text { slowly } \\
\text { (over } 3 \mathrm{~min} . \text { ) }\end{array}$ & $\begin{array}{l}\text { Onset: } 3-10 \text { min. } \\
\text { Peak: } 30 \text { min. } \\
\text { Duration: } 2-4 \text { hrs. } \\
\text { Caution: cardiac monitoring/QT interval issue }\end{array}$ \\
\hline Midazolam & $\begin{array}{l}0.05 \mathrm{mg} / \mathrm{kg} \text { IVslowly } \\
\text { (over } 3 \mathrm{~min} \text {.) } \\
0.1-0.3 \mathrm{mg} / \mathrm{kg} \mathrm{IM}\end{array}$ & $\begin{array}{l}\text { Onset: } 1-5 \mathrm{~min} \text {. (IV/) } 15 \mathrm{~min} \text {. (IM) } \\
\text { Peak: } 1-5 \mathrm{~min} \text { (IV)/30-60 min. (IM) } \\
\text { Duration: } 2-6 \mathrm{hr} \text {. (IV \& IM) }\end{array}$ \\
\hline \multicolumn{3}{|c|}{ Narcotics - (not in infants less than 3 mos.) } \\
\hline Meperidine & $\begin{array}{l}1 \mathrm{mg} / \mathrm{kg} \mathrm{IM}, \mathrm{SQ}, \text { or IV } \\
\text { (slowly) }\end{array}$ & \\
\hline Morphine & $\begin{array}{l}0.1 \mathrm{mg} / \mathrm{kg} / \mathrm{M}, \mathrm{SQ} \text {, or } \\
\text { IV (slowly) }\end{array}$ & \\
\hline Butorphanol & $\begin{array}{l}0.01-0.02 \mathrm{mg} / \mathrm{kg} \mathrm{IV} \\
\text { (slowly) }\end{array}$ & \\
\hline Fentanyl & $\begin{array}{l}1-3 \mathrm{mcg} / \mathrm{kg} \\
(0.001-0.003 \mathrm{mg} / \mathrm{kg})\end{array}$ & $\begin{array}{l}\text { Diminished sensitivity to } \mathrm{C0} 2 \text { stimulation may } \\
\text { persist longer than depression of resp. rate }\end{array}$ \\
\hline \multicolumn{3}{|l|}{ Antagonists } \\
\hline $\begin{array}{l}\text { Naloxone } \\
\text { (for narcotics) }\end{array}$ & $\begin{array}{l}0.01-0.10 \mathrm{mg} / \mathrm{kg} / \mathrm{V} \text { to } \\
\text { desired effect }\end{array}$ & Brief duration of action (30 to $45 \mathrm{~min}$.) \\
\hline \begin{tabular}{|l} 
Physostigmine (for \\
anticholinergic syndrome)
\end{tabular} & $\begin{array}{l}0.015-0.025 \mathrm{mg} / \mathrm{kg} \text { to } \\
\text { desired effect }\end{array}$ & $\begin{array}{l}\text { Watch for cholinergic side effects } \\
\text { (bradycardia, emesis, cramping, salivation) }\end{array}$ \\
\hline $\begin{array}{l}\text { Flumazenil (for } \\
\text { benzodiazepines) }\end{array}$ & $\begin{array}{l}0.1-0.2 \mathrm{mg} \text { (partial } \\
\text { antagonism) } \\
0.4-1.0 \mathrm{mg} \text { (complete } \\
\text { antagonism) }\end{array}$ & $\begin{array}{l}\text { Benzodiazepine withdrawl-induced seizures; } \\
\text { residual sedation/ hypoventilation }\end{array}$ \\
\hline
\end{tabular}

